wound infections after cardiac surgery. J Thorac Cardiovasc Surg. 2017;154 1320-3.e1.

4. Lazar HL, VanderSalm T, Engelman R, Orgill D, Gordon S. Prevention and management of sternal wound infections. J Thorac Cardiovasc Surg. 2016;152: 962-72.

5. D'Agostino RS, Jacobs JP, Badhwar V, Fernandez FG, Paone G, Wormuth DW, et al. The Society of Thoracic Surgeons adult cardiac surgery database: 2018 update on outcomes and quality. Ann Thorac Surg. 2018;105:15-23.

https://doi.org/10.1016/j.jtcvs.2018.04.067

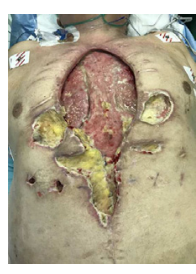

\section{VANCOMYCIN PASTE IN STERNAL WOUND INFECTION \\ PROPHYLAXIS-A \\ GENUINE DEBATE OR \\ FUTILE ATTEMPTS TO JUSTIFY FLAWED STUDY?}

\section{Reply to the Editor:}

We read, again with unextinguished enthusiasm, the response letter to our meta-analysis ${ }^{1}$ by Dr Body et al, ${ }^{2}$ in which the authors criticize our methodological approaches to the assessment of effectiveness of vancomycin paste applied to the sternal edges to prevent sternal wound infections (SWIs) after heart surgery. Our enthusiasm is driven mainly by the fact that superstitions and different opinions on the matter of topical antibiotics in cardiac surgery, albeit largely resolved in a recent American Association for Thoracic Surgery expert consensus report, ${ }^{3}$ still add fuel to the fierce debate.

That said, we feel obliged to clarify the issues raised by a recent report in the Annals of Thoracic Surgery, ${ }^{4}$ which served as an underpinning for our meta-analysis. Namely, the authors, in contrast to previous reports, ${ }^{5-7}$ showed that vancomycin paste neither reduced the incidence of deep SWI (DSWI) nor was its use a negative predictor of DSWI in a multivariate analysis. In the meta-analysis, this particular study was found to be the source of substantial heterogeneity in the analysis of SWIs, the reason being, apart from unbalanced baseline characteristics of the patients, certain methodologic flaws as discussed elsewhere in detail, ${ }^{1,8}$ which beyond doubt suggested a strong influence of factors other than topical vancomycin must have driven the results toward null in the analysis by Lander et al. ${ }^{4}$

Significant unbalance was seen in particular when data were stratified according to time assays. Indeed, vancomycin paste was used only in $25 \%$ of patients in the first 7 years of the study period (2321 of 9413 from 2003 to 2010 ) with a $1.29 \%$ rate of DSWI (121 DSWIs in 9413 patients). In the second time period (2011-2015), vancomycin paste was used in $53 \%$ of patients (2676 of 5079 patients) with a rate of DSWI cut nearly fivefold $(0.29 \% ; 15$ DSWIs in 5079 patients).

To better illustrate this, we designed a simple time-based analysis only taking into account data published in the report by Lander et $\mathrm{al}^{4}$ (Figure 1). We plotted percentage prevalence of vancomycin paste use against percentage incidence of DSWI across reported time ranges. Even from the chart, it is intuitive to observe that with more vancomycin use, the number of DSWIs significantly decreases. Using simple linear regression: $\beta$ coefficient $=-0.94$ (95\% confidence interval, -1.18 to $-0.70 ; P<.001)$. Of note, risk for developing DSWI in the series was still reduced by $26 \%$ (risk ratio, $0.74 ; 95 \%$ confidence interval, 0.51-1.07) although this was not significant.

Dr Body's claim that our meta-analysis fails to appreciate that: (1) 2 previous studies ${ }^{5,7}$ used historical controls, (2) significant publication bias was present in the analysis, and last, (3) propensity matching performed in 2 of the included studies is not enough to account for unmeasured

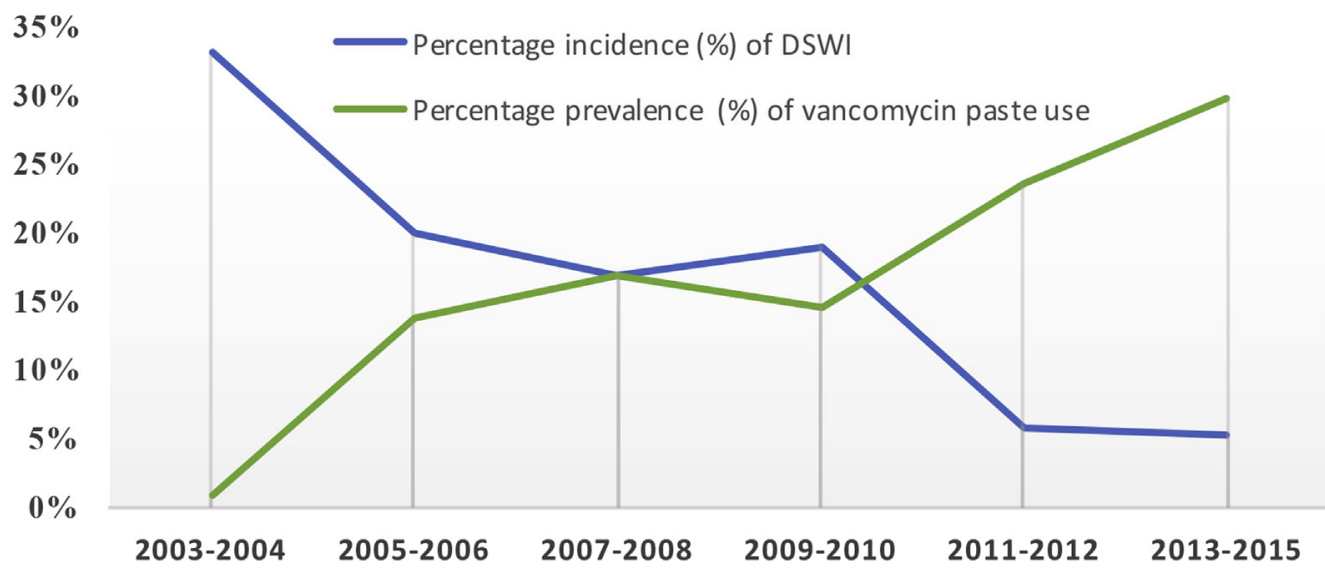

FIGURE 1. Percentage prevalence of vancomycin paste use and percentage incidence of deep sternal wound infection (DSWI) across reported time ranges in the article by Lander et al. ${ }^{4}$ 
Authors have nothing to disclose with regard to commercial support.

confounders can be readily addressed; to answer comments 1 and 3, we couldn't agree more on the fact that inclusion of only observational data might lead to an increase of the selection bias risk, that is however, inherent to this kind of analysis, granted the absence of randomized prospective studies. However, by propensity matching the influence of baseline confounders, which might have led to groups of patients receiving vancomycin and others not, is minimized. It is, in fact, in the report by Lander et $\mathrm{al}^{4}{ }^{4}$ that vancomycin-receiving patients were older, had higher body mass indexes (BMI > 30: $33.3 \%$ vs $30.3 \%$ ), statistically more often presented with diabetes, hypertension, chronic lung disease, and had their chest reopened $30 \%$ more often than controls. Common sense would suggest that all these factors, however, not accounted for in any of the analyses by Lander et al, are known predictors of sternal wound infections ${ }^{9}$ and would have reduced the efficacy estimate of vancomycin paste in the first place.

Regarding comment 2, suggesting evidence of publication bias in the meta-analysis, we acknowledge that poses a serious limitation to the analysis. Interestingly, it is indeed the study by Lander et $\mathrm{al}^{4}$ that was identified as a source of substantial heterogeneity and thus publication bias according to visual assessment of the "funnel plot" previously (see Figure E2 ${ }^{1}$ ) and as well now using linear regression to test asymmetry of the plot (Egger test ${ }^{10}$ $P$ value [2-tailed] $=.031$; after omission of Lander et al ${ }^{4}$ $P$ value $=.109)$.

To conclude, we believe that efforts by Dr Body to justify the negative or in fact nonsignificant-only results of the recent article, ${ }^{4}$ should better be directed toward proper interpretation of their own data rather than arbitrarily excluding 3 studies from meta-analysis of 4 and proving their point. Vancomycin paste but also other topical antibiotics $^{11}$ are relatively inexpensive, are easy to handle, have no local or systemic side effects, and are proven safe and effective across a diversity of surgical fields. We again agree with Dr Body that vancomycin paste cannot eliminate each single infection and "changes in patient acuity and medical care, antibiotic prophylaxis, surgical technique, and important changes in glycemic control" taking place in the past decade have elucidated our perception of DSWIs; however, because the available data and expert guidelines support the use of topical antibiotics, a single flawed study cannot tell us otherwise.

\footnotetext{
Mariusz Kowalewski, $M D^{a, b}$ Giuseppe M. Raffa, $M D^{c, d}$ Roberto Lorusso, $M D, P h D^{c}$
}

Lech Anisimiowicz, $M D, P h D^{e}$

Harold L. Lazar, MD, PhD

Piotr Suwalski, MD, PhD ${ }^{a, g}$

${ }^{a}$ Clinical Department of Cardiac Surgery Central Clinical Hospital of Ministry of Interior

Warsaw, Poland

${ }^{b}$ Cardiothoracic Research Centre Collegium Medicum

Nicolaus Copernicus University Bydgoszcz, Poland

${ }^{c}$ Cardio-Thoracic Surgery Department Heart and Vascular Centre Maastricht University Medical Centre Maastricht, The Netherlands ${ }^{d}$ Department for Treatment and Study of Cardiothoracic Diseases and Cardiothoracic Transplantation and Department of Anesthesia and Intensive Care IRCCS_ISMETT (Istituto Mediterraneo per i Trapianti e

Terapie ad alta Specializzazione) Palermo, Italy

${ }^{e}$ Department of Cardiac Surgery Dr Antoni Jurasz Memorial University Hospital Bydgoszcz, Poland

${ }^{f}$ Division of Cardiac Surgery The Boston University School of Medicine

Boston, Mass

${ }^{g}$ Faculty of Health Science and Physical Education Pulaski University of Technology and Humanities Radom, Poland

\section{References}

1. Kowalewski M, Raffa GM, Szwed KA, Anisimowicz L. Meta-analysis to assess the effectiveness of topically used vancomycin in reducing sternal wound infections after cardiac surgery. J Thorac Cardiovasc Surg. 2017;154: 1320-3.e1323.

2. Lander HL, Ejiofor JI, McGurk S, Tsuyoshi K, Shekar P, Xu X, et al. Vancomycin paste still does not reduce the incidence of deep sternal wound infection after cardiac surgery. J Thorac Cardiovasc Surg. 2018;156:1125-6.

3. Lazar HL, Salm TV, Engelman R, Orgill D, Gordon S. Prevention and management of sternal wound infections. J Thorac Cardiovasc Surg. 2016;152: 962-72.

4. Lander HL, Ejiofor JI, McGurk S, Tsuyoshi K, Shekar P, Body SC. Vancomycin paste does not reduce the incidence of deep sternal wound infection after cardiac operations. Ann Thorac Surg. 2017;103:497-503.

5. Lazar HL, Ketchedjian A, Haime M, Karlson K, Cabral H. Topical vancomycin in combination with perioperative antibiotics and tight glycemic control helps to eliminate sternal wound infections. J Thorac Cardiovasc Surg. 2014;148:1035-40.

6. Vander Salm TJ, Okike ON, Pasque MK, Pezzella AT, Lew R, Traina V, et al Reduction of sternal infection by application of topical vancomycin. $J$ Thorac Cardiovasc Surg. 1989;98:618-22.

7. Hamman BL, Stout LY, Theologes TT, Sass DM, da Graca B, Filardo G, et al Relation between topical application of platelet-rich plasma and vancomycin and severe deep sternal wound infections after a first median sternotomy. Am J Cardiol. 2014;113:1415-9.

8. Lazar HL. The use of vancomycin paste to reduce sternal wound infections after cardiac surgery-why is this still a "sticky" subject. J Thorac Cardiovasc Surg. 2017; $154: 1324-5$.

9. Gatti G, Dell'Angela L, Barbati G, Benussi B, Forti G, Gabrielli M, et al A predictive scoring system for deep sternal wound infection after bilateral internal thoracic artery grafting. Eur J Cardiothorac Surg. 2016;49: 910-7. 
10. Egger M, Davey Smith G, Schneider M, Minder C. Bias in meta-analysis detected by a simple, graphical test. BMJ. 1997;315:629-34.

11. Kowalewski M, Pawliszak W, Zaborowska K, Navarese EP, Szwed KA, Kowalkowska ME, et al. Gentamicin-collagen sponge reduces the risk of sternal wound infections after heart surgery: meta-analysis. J Thorac Cardiovasc Surg. 2015;149:1631-40.e6.

https://doi.org/10.1016/j.jtcvs.2018.04.072 